\title{
Seasonal Variation of Nanoparticles in the Ortles Glacier, Eastern Alps
}

Hendrik Colijn, Aja Ellis, John Olesik and Paolo Gabrielli

Ohio State University, Columbus, Ohio, United States

Glaciers are natural time capsules reflecting the atmospheric contents at the time the snow layer was deposited [1]. Recent work on the Ortles Glacier in the Stelvio National Park of the Eastern Alps (Italy) has recovered ice cores dating as far back as 7000 years. [2] To date, little work has been done on submicron particulates in ice cores since these particles tend to be too small to be detected by the most common analytical techniques. We show here data collected from the 2016 summer and winter shallow snow deposits from the Ortles Glacier. These samples were collected and prepared under careful clean conditions to avoid contamination. [3]

Glacial melt samples were initially analyzed by single particle ICP-MS [3] and showed a strong variation in the detectable number of $\mathrm{Ni}$ and $\mathrm{Cr}$ containing particles between the summer and winter samples (Fig. 1). The melt samples were dispersed on a carbon film TEM grid and examined in an FEI/Thermo Scientific Tecnai F20 STEM. The EDX data were recorded with an EDAX XLT windowless SDD detector using the EDAX TEAM and the Genesis "Particles" software.

The summer 2016 sample had a higher number of particles whose composition is roughly that of a type 300 series stainless steel than the winter sample. Although the composition isn't exact, the presence of approx. 2\% Mo suggests that these particles are from a type 316 stainless steel process. Many of the stainless steel particles were embedded in a silicate matrix with the steel particles in the 10-20 nm size range. The winter samples had much less stainless steel but instead had a higher number of $\mathrm{Cu}_{2} \mathrm{~S}$ particles. The $\mathrm{Cu}_{2} \mathrm{~S}$ particles were not observed in the sample from summer 2016. These copper sulfides were somewhat larger, approx. $100-200 \mathrm{~nm}$. Both samples also contained natural minerals (iron oxides, aluminum magnesium silicates, titania, alumina, etc.) as well.

There are a large number of Electric Arc Furnace (EAF) operations in the Po River valley which are known to generate fine dust pollution (up to 40\% PM2.5 [5, 6]). The dust collection bag filters are unlikely to capture the nanoparticles. Prevailing winds (winter) and atmospheric convection (summer) can then carry the dust from the lowlands to the higher elevation of the glacier. Analysis of the wind patterns on Mt. Ortles through the seasons can give significant clues as to the origin of the nanoparticulate dust. [3]

Conventional methods miss a large number of sub-micron particles that are present in Alpine glacial deposits. STEM EDX analysis can provide a useful perspective of this size fraction and suggest sources of the pollution. [7] 


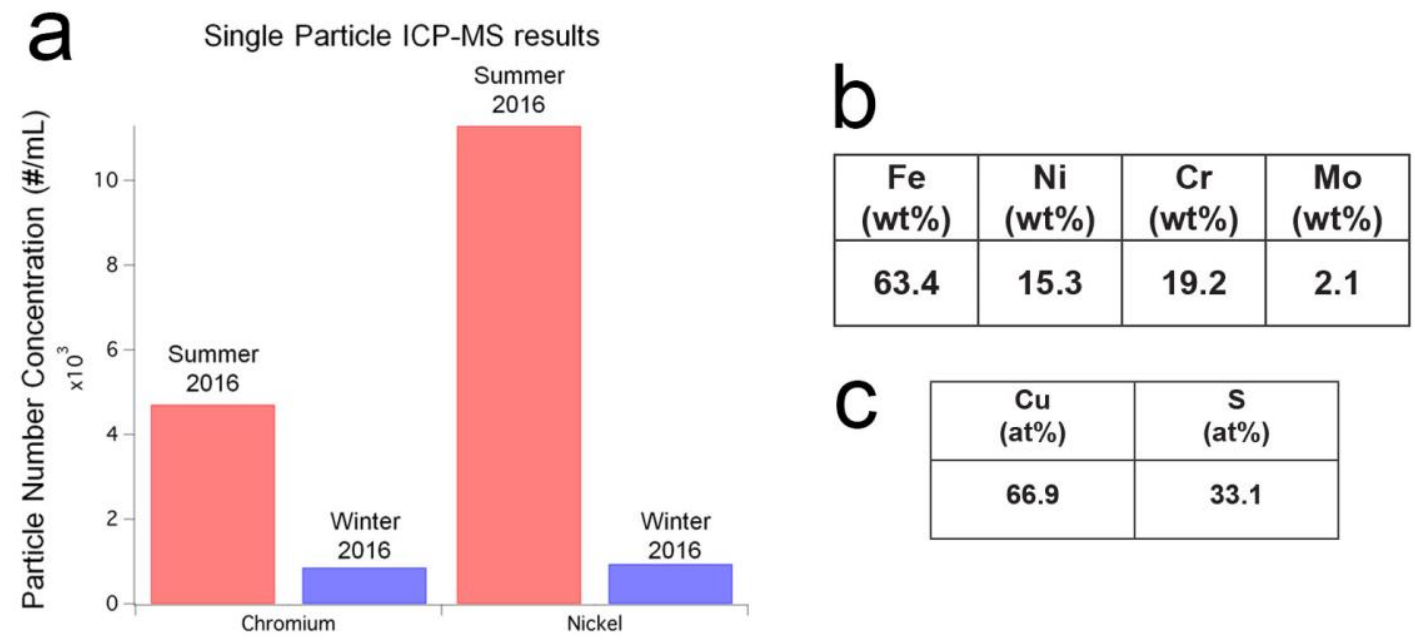

Figure 1. (a) ICP-MS Particle concentration - Summer snow deposit (red) and Winter snow deposit (blue) [4]; (b) Typical stainless steel particle composition (type 316 stainless); (c) Typical copper sulfide particle composition $(\mathrm{Cu} 2 \mathrm{~S})$
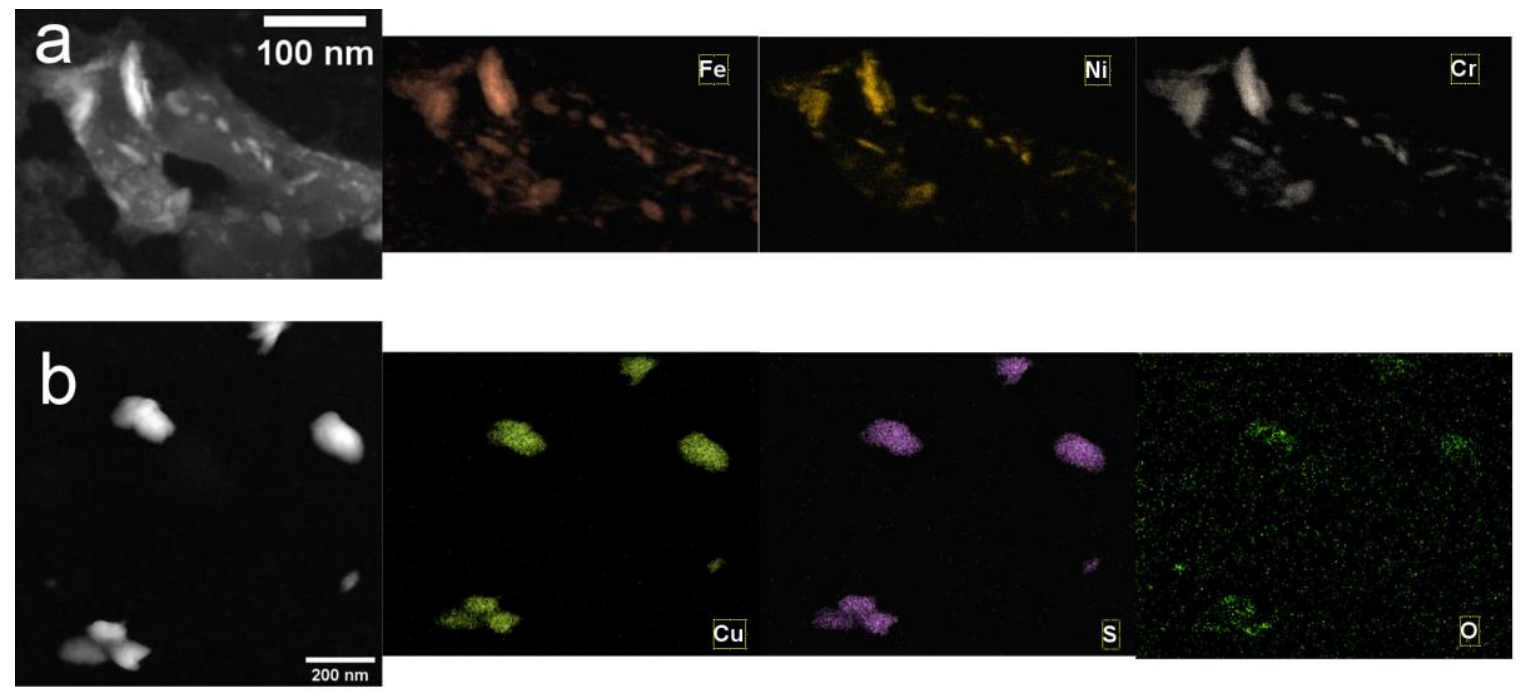

Figure 2. (a) Typical particle with Stainless steel inclusions from summer snow deposit (net counts).; (b) Typical copper sulfide ( $\mathrm{Cu} 2 \mathrm{~S}$ ) particle from winter snow deposit (net counts).

\section{References}

[1] EPICA community members, Nature 429 (2004) p.623.

[2] Gabrielli, P., et al., The Cryosphere 10 (2016) p. 2779.

[3] Gabrieli, J., et al., Atmos. Chem. Phys. 11 (2011) p. 8087

[4] unpublished data, J.W. Olesik, P.G Gabrielli, A. Ellis, (2019)

[5] Simonyan L, Alpatova A, Demidova N, J Materials Research and Tech, 8 (2019), p.1607.

[6] Cappelletti R, et al., J Occupational Medicine and Toxicology. 11 (2016), article 7.

[7] The authors acknowledge support from NSF awards no. 1060115 \& no. 1461422 and from the Ripartizione Opere idrauliche e Ripartizione Foreste of the autonomous province of Bolzano and the Stelvio National Park as well as The Ohio State University, the OSU Institute for Materials Research, The Byrd Polar Research Center, and the Ohio Third Frontier Research Scholar program. 